\title{
PARIWISATA KABUPATEN NGADA BERBASIS PETA DIGITAL
}

\author{
Jelita Citrawati Jihan ${ }^{1)}$, Kristianus Resi Gae ${ }^{1)}$ \\ ${ }^{1)}$ Program Studi Perencanaan Wilayah dan Kota, Fakultas Teknik Sipil dan Perencanaan, \\ Universitas PGRI Adi Buana Surabaya \\ email: jelita@unipasby.ac.id
}

\begin{abstract}
Abstrak
Kontribusi sektor pariwisata di Kabupaten Ngada menurut Produk Domestik Regional Bruto (PDRB) 2014-2016 meningkat rata-rata 6,65\% per tahun. Oleh karena itu, tujuan dari penelitian ini adalah untuk mengidentifikasi potensi atraksi dengan teknik analisis deskriptif kualitatif, menganalisis sistem keterkaitan antara atraksi dengan teknik analisis sistem keterkaitan, dan pengembangan pariwisata berbasis peta digital yaitu WebGIS. Selain itu, teknik pengumpulan data meliputi observasi, dokumentasi dan pemetaan Sistem Informasi Geografis (SIG). Hasil survei menunjukkan dua lokasi wisata tanpa tempat wisata, yaitu: Taman Wisata Alam 17 Pulau Riung dan Danau WawoMuda. Objek wisata tinju tradisional (Saghi) hanya ada di Sumber Air Panas Mangeruda. Sementara itu daya tarik kontribusi sektor pariwisata di Kabupaten Ngada menurut Produk Daerah Tari Jai adalah di Kampung Tua Bela, Bena, Nage, Wogo, Gurusina, dan Ekowisata Lekolodo. Selanjutnya, pengkodean SIG berbasis Web dan peta Google sebagai basemap, untuk menampilkan website menggunakan sistem koneksi server panel kontrol XAMPP. Rute sebagai arah dari lokasi pengguna ke situs wisata, dalam hal jarak, rute transportasi umum dan layanan lainnya. Selain itu, pariwisata WebGIS diharapkan dapat membantu wisatawan dan kawasan memainkan peran aktif dalam pengembangan pariwisata.
\end{abstract}

Kata Kunci: Kabupaten Ngada, Web GIS, Pariwisata

\begin{abstract}
The contribution of the tourism sector in Ngada Regency according to the 2014-2016 Gross Regional Domestic Product (GRDP) increased by an average of $6.65 \%$ per year. Therefore, the purpose of this research is to identify potential attractions with qualitative descriptive analysis techniques, analyze the linkage system between attractions with linkage system analysis techniques, and develop digital tourism based maps, namely WebGIS. In addition, data collection techniques include observation, documentation and mapping of Geographic Information Systems. The survey results show two tourist sites without tourist attractions, namely: Taman Wisata Alam 17 Riung Island and Lake WawoMuda. Traditional boxing attractions (Saghi) only exist in Mangeruda Hot Springs. Meanwhile the appeal of the tourism sector's contribution in the Ngada Regency according to the Jai Dance Regional Products is in the villages of Bela, Bena, Nage, Wogo, Gurusina, and Lekolodo Ecotourism. Furthermore, the coding of Web-based GIS and Google maps as a basemap, for showing using the XAMPP control panel server connection system. Route as the direction from the user's location to the tourist site, in terms of distance, public transportation routes and other services. In addition, WebGIS tourism is expected to help tourists and the region play an active role in tourism development.
\end{abstract}

Keywords: Ngada District, Web GIS, Tourism 


\section{PENDAHULUAN}

Sektor Pariwisata merupakan salah satu yang mendapatkan perhatian khusus dari program Nawa Cita, sehingga diharapkan mampu sebagai leading sector dan penggerak sector industry dan ekonomi lainnya. Data Produk Domestik Regional Bruto (PDRB) menurut Atas Dasar Harga Konstan 2010 menunjukkan Tahun 20142016 kontribusi sektor pariwisata di Kabupaten Ngada rata-rata meningkat sebesar 6,65\% per tahun. Kondisi sebagian besar objek wisata di Kabupaten Ngada tergolong masih dalam kondisi alami dan belum tergarap secara optimal, juga prasarana dan sarana penunjangnya yang masih sangat minim seperti: perhotelan, restauran dan cafe.

Pariwisata berbicara tentang sisi komponen produk wisata (tourism supply side) yang bersifat sistem destinasi pariwisata yang menawarkan komponen utama yaitu objek dan daya tarik wisata yang berbasis alam, budaya maupun minat khusus (Rifiyan and Manullang 2015). Oleh karena itu, daerah dituntut untuk mampu berkreasi dan berinovasi dalam menggali potensi dan sumber pendapatan, yang bercirikan bentuk penciptaan dan pemanfaatan proses baru, produk baru, jasa baru dan metode penyampaian yang baru, yang menghasilkan perbaikan yang signifikan dalam hal efisiensi, efektivitas maupun kualitas menjadi bermakna di mata public (Bahrudin 2017).

Rencana pengembangan kawasan wisata di Kabupaten Ngada adalah meliputi pengembangan potensi obyek daya tarik wisata, penyediaan fasilitas pendukung wisata berupa perhotelan, restaurant dan cafe, pelayanan informasi jasa dan fasilitas pendukung lainnya, pengembangan akses menuju lokasi wisata baik dalam bentuk pembangunan fisik maupun sistem manajemen transportasi, peningkatan promosi wisata sampai pada mancanegara guna menarik minat wisatawan mancanegara, peningkatan peran serta masyarakat dalam mengembangkan kawasan wisata, serta meningkatkan promosi terhadap wisata kawasan budaya sehingga bermanfaat bagi masyarakat setempat (Peraturan daerah Kabupaten Ngada Nomor 3 Tahun 2012 tentang
Rencana Tata Ruang Wilayah Kabupaten Ngada tahun 2012-2032).

Peningkatan promosi wisata sampai pada mancanegara membutuhkan inovasi melalui identifikasi potensi wisata dan kajian sistem informasi berupa peta digital antar obyek wisata sehingga dapat mempermudah wisatawan untuk memilih obyek wisata dan menuju lokasi. Manfaat lainnya dapat mengetahui hubungan antar sektor yang berpengaruh dalam pengembangan pariwisata dan keterkaitan antar obyek wisata di Kabupaten Ngada.

\section{Identifikasi Obyek Wisata}

Daya Tarik Wisata

Menurut (Kirom, Sudarmiatin, dan Adi Putra 2016), daya tarik wisata didefinisikan sebagai segala sesuatu yang menarik dan bernilai untuk dikunjungi dan dilihat. Daya tarik wisata dapat dikelompokan menjadi tiga jenis, yaitu:

a. Daya tarik wisata alam

Daya tarik wisata alam adalah segala sesuatu yang memiliki keunikan, keindahan, keaslian serta nilai berupa keanekaragaman alam hasil ciptaan Tuhan.

b. Daya Tarik Wisata Budaya

Daya tarik wisata budaya adalah segala sesuatu yang memiliki keunikan, keindahan, keaslian serta nilai berupa keanekaragaman hasil budaya manusia.

c. Daya Tarik Wisata Buatan

Daya tarik wisata buatan adalah segala sesuatu yang memiliki keunikan dan keindahan dari hasil buatan manusia baik secara langsung maupun tidak langsung.

\section{Sarana Wisata}

Sarana wisata adalah segala bentuk fasilitas yang memberikan pelayanan bagi wisatawan untuk segala kebutuhanya selama tinggal atau berkunjung pada suatu daerah tujuan wisata, contohnya hotel, restaurant, bar, shopping center, souvenir shop untuk memenuhi kebutuhan perjalanan wisata perlu disediakan fasilitas mulai dari pemenuhan kebutuhan sejak berangkat dari tempat tinggal wisatawan, selama berada di tempat destinasi wisata, maupun saat wisata kembali ke tempat semula (Rosyidah, Sunarti, and Pangestuti 
2017). Sarana pendukung wisata terbagi atas:

a. Sarana pokok kepariwisataan

Adalah perusahan yang hidup dan kehidupanya sangat tergantung kepada arus kedatangan orang yang melakukan perjalanan wisata, termaksud ke dalam kelompok ini adalah: travel agent dan tour operator, perusahan-perusahan angkutan wisata, hotel dan jenis akomodasi lainya.

b. Sarana pelengkap kepariwisataan

Adalah perusahan-perusahan atau tempat-tempat yang menyediakan fasilitas untuk rekreasi yang fungsinya tidak hanya melengkapi sarana pokok kepariwisataan dapat lebih lama tinggal pada suatu daerah tujuan wisata. Termaksud kedalam kelompok ini adalah sarana olahraga seperti lapangan tenis, lapangan golf, kolam renang, permainan bowling, dan daerah perburuan.

c. Sarana penunjang kepariwisataan

Adalah perusahan yang menunjang sarana pelengkap dan sarana pokok dan berfungsi tidak hanya membuat wisatawan lebih lama tinggal pada suatu daerah tujuan wisata, tetapi fungsi yang lebih penting adalah agar wisatawan lebih banyak mengeluarkan atau membelanjakan uangnya di tempat yang dikunjungi. Termaksud dalam kelompok ini adalah night club, steambath, kasino.

Aksesbilitas

Menurut Sumarabawa (2013) dalam (Hermawan 2017) aksesbilitas yang baik akan menentukan mudah atau tidaknya lokasi untuk dijangkau. Selain itu jaringan jalan juga merupakan salah satu yang berpengaruh terhadap kelancaran pelayanan umum yang sangat penting. Aksesbilitas sangat penting dalam pengembangan destinasi wisata karena menjamin keterjangkauan serta efetifitas dan efesiensi bagi kunjungan wisata. Beberapa hal yang mempengaruhi aksesbilitas suatu tempat adalah kondisi jalan, tarif angkutan jenis kendaraan, jaringan transportasi, jarak tempuh dan waktu tempuh.

Promosi
Promosi pariwisata adalah kampanye dan propaganda kepariwisataan yang didasarkan atas rencana atau program yang teratur dan secara kontinyu. Promosi ini ditujukan kepada masyarakat dalam negeri sendiri dengan maksud dan tujuan menggugah pandangan masyarakat agar mempunyai kesadaran akan kegunaan pariwisata baginya, sehingga industri pariwisata di negeri ini memperoleh dukungan (Rifiyan and Manullang 2015). Promosi dapat dibedakan menjadi dua yaitu:

a. Promosi Langsung

Sasaran terakhir dari semua kegiatan pemasaran dan promosi ialah orangorang yang akhirnya megeluarkan uang untuk mengadakan perjalanan wisata: si calon wisatwan atau wisatawan potensial. Berhasil-tidaknya promosi kepariwisataan akan kelihatan dari banyaknya jumlah orang yang sungguhsungguh membeli produk pariwisata yang dipromosikan. Untuk tujuan tersebut, makin besar daya tarik produk pariwisata makin baik Untuk keperluan itu pada waktu-waktu tertentu yang tepat diadakan kegiatan promosi.

b. Promosi Tidak Langsung

Promosi tidak langsung pertama-tama ditujukan kepada penyalur produk pariwisata, seperti biro perjalanan umum dan cabang-cabangnya, agen perjalanan, organisasi-organisasi perjalanan, dan sebagainya. Mereka diberi tugas untuk mempromosikan potensi pariwisata yang ada sehingga dapat menjadi daya tarik tersendiri bagi wisatawan.

\section{METODE}

1. Pengumpulan data. Pengambilan data obyek wisata, persebaran hotel, restoran, toko cenderamata, rumah makan, kantor pos, moda transportasi dari data survey GPS, sedangkan data jumlah moda transportasi dari Dinas setempat.

2. Analisis deskriptif, digunakan dalam mengidentifikasi potensi obyek wisata dalam bentuk table dan foto. Data yang digunakan adalah daya tarik wisata alam, buatan dan budaya, sarana pendukung, aksesbilitas dan promosi. 
3. Pemetaan SIG. Prahasta 2009, mendefinisikan Sistem Informasi Geografis memiliki kemampuan untuk menghubungkan berbagai data pada suatu titik tertentu di bumi, menggabungkannya, menganalisis dan memetakan hasilnya (Marlena and Aspriyono 2014).
4. Pengkodean. Perangkat lunak sebagai penunjang adalah notepad+++ untuk merancang code, XAMPP control panel merupakan tool yang menyediakan paket perangkat lunak ke dalam satu paket (Atas et al. 2016).

Pelaksanaan dari pembuatan WebGIS dapat digambarkan dalam diagram alir berikut.

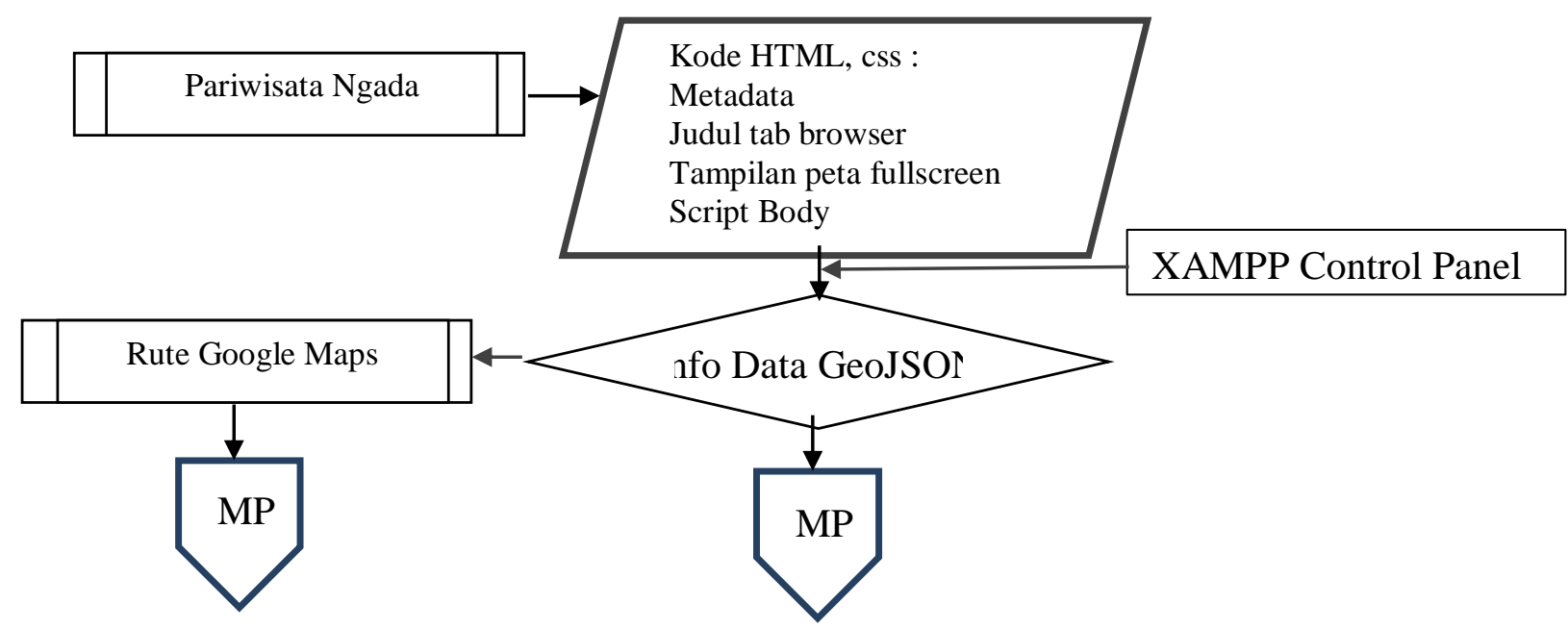

Gambar 1. Pelaksanaan dari pembuatan WebGIS

\section{HASIL DAN PEMBAHASAN}

Kabupaten Ngada adalah salah satu kabupaten yang berada di Pulau Flores provinsi Nusa Tenggara Timur. Kabupaten Ngada memiliki 12 kecamatan dan 151 desa atau kelurahan. Kondisi topografi sebesar $60,23 \%$ wilayah berbukit dengan tingkat kemiringan lahan diatas $40 \%$ dan berada padsa ketinggian 0-500 mdpl. Kabupaten Ngada tergolong daerah yang beriklim tropis dan terbentang hampir sebagian besar padang rumput, juga ditumbuhi pepohonan seperti kemiri, asam, kayu manis, lontar dan sebagainya serta kaya dengan fauna, antara lain hewanhewan besar, hewan-hewan kecil, unggas, binatang menjalar, binatang liar dan binatang purba seperti Varanus Riungensis (Mbou) di Riung (Ngada Dalam Angka 2017). Definisi dari pariwisata sebagai aktifitas yang dilakukan orang-orang yang mengadakan perjalanan untuk dan di tinggal di luar kebiasaan lingkungannta dan tidak lebih dari satu tahun berturut-turut untuk kesenangan, bisnis dan keperluan lain (Choridatul, Wahyu, and Sudarti 2018). 


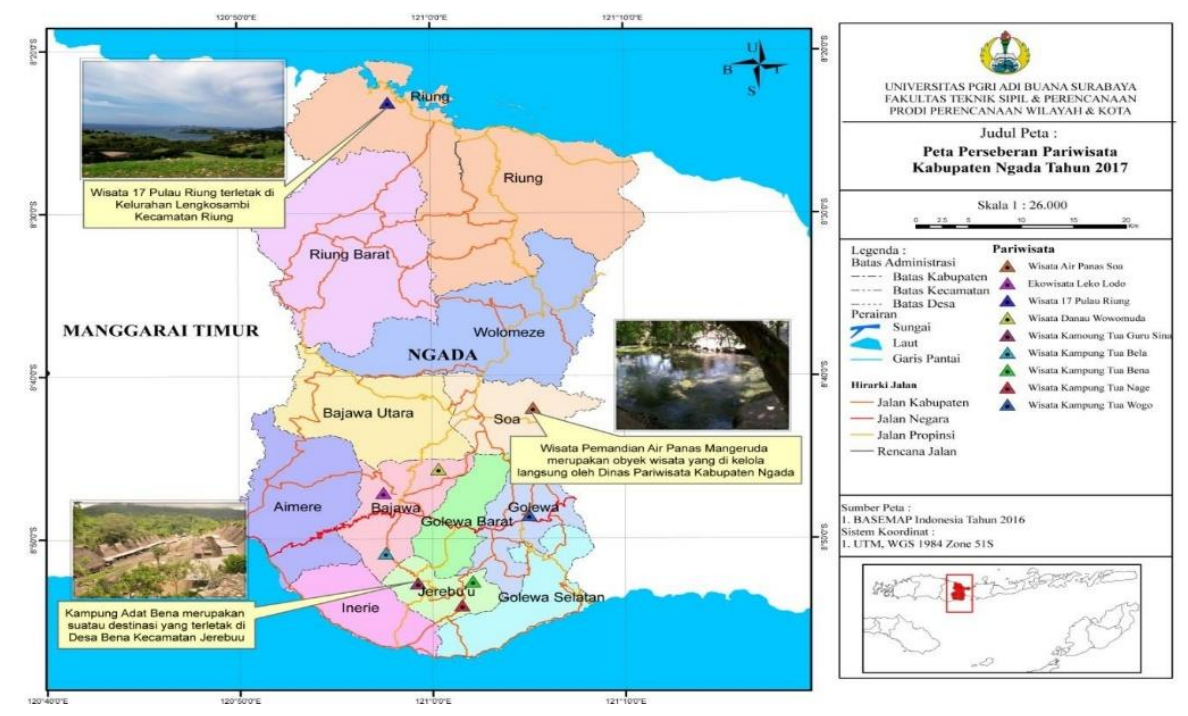

Gambar 2. Peta Administrasi Kabupaten Ngada

Perkembangan pariwisata berdampak pada perkembangan ekonomi masyarakat setempat, social dan budaya Kabupaten Ngada. Untuk itu diperlukan strategi daya tarik, sarana pendukung, aksesbilitas dan promosi. Berdasarkan hasil pengamatan di lapangan strategi obyek wisata Kabupaten Ngada:

a. Daya Tarik

Taman Wisata Alam 17 pulau Riung: menawarkan wisata 17 pulau, terumbu karang, pulau kelelawar dan hewan purba sejenis komodo (Mbou)

Pemandian Air Panas Mangeruda: Kolam Pemandian Air Panas, wisata religi, atraksi wisata tinju adat (Saghi) Danau Wawo Muda: Kawah 3 warna dan sunrise
Kampung Tua Bela, Kampung Tua Bena, Kampung Tua Nage, Kampung Tua Gurusina

Kampung Tua Wogo: Berupa Batu peninggalan megalitikum Ngadhhu dan Bhaga dan atraksi wisata berupa tarian jai

Ekowisata Lekolodo: Berupa Air terjun pemandangan gunung inerie.

b. Sarana Pendukung

Taman Wisata Alam 17 pulau Riung: Tersedia 3 unit hotel, 2 unit restoran dan 1 unit toko cendramata.

Pemandian Air Panas Mangeruda: Tersedia 1 unit hotel dan 1unit restoran Belum tersedia sarana pendukung: Kampung Tua Bela, Kampung Tua Bena, Kampung Tua Nage, Kampung Tua Gurusina Kampung Tua Wogo dan Ekowisata Lekolodo

c. Aksesbiltas

Tabel 1 Aksesbilitas Obyek Wisata Kabupaten Ngada

\begin{tabular}{|c|c|c|c|c|}
\hline Obyek Wisata & $\begin{array}{l}\text { lebar } \\
\text { jalan }(\mathrm{m})\end{array}$ & $\begin{array}{l}\text { kondisi } \\
\text { jalan }\end{array}$ & $\begin{array}{l}\text { lahan } \\
\text { parkir }\end{array}$ & Moda dan Akses kendaraan \\
\hline $\begin{array}{l}\text { Taman Wisata } \\
\text { Alam } 17 \\
\text { Pulau Riung }\end{array}$ & 3,15 & baik & Ada & $\begin{array}{l}\text { kendaraan roda } 2 \text {, kendaraan } \\
\text { roda } 4 \text { dan trayek angkutan umum } \\
\text { Bajawa Riung, Soa - Riung, } \\
\text { Jerebuu - Riung }\end{array}$ \\
\hline $\begin{array}{l}\text { Pemandian Air } \\
\text { Panas } \\
\text { Mangeruda }\end{array}$ & 3,50 & baik & Ada & $\begin{array}{l}\text { kendaraan roda } 2 \text {, roda } 4 \text { dan } \\
\text { trayek angkutan umum Bajawa - } \\
\text { Ngoronale - Soa, Riung - } \\
\text { Marunggela - Soa, Jerebuu - Soa }\end{array}$ \\
\hline $\begin{array}{l}\text { Danau } \\
\text { WawoMuda }\end{array}$ & 3,50 & baik & Ada & $\begin{array}{l}\text { kendaraan roda 2, roda } 4 \text { dan } \\
\text { trayek Angkutan umum Bajawa - }\end{array}$ \\
\hline
\end{tabular}




\begin{tabular}{|c|c|c|c|c|}
\hline & & & & Ngoronale - Soa - Marunggela - \\
\hline $\begin{array}{l}\text { Kampung Tua } \\
\text { Bela }\end{array}$ & 3,50 & baik & Ada & $\begin{array}{l}\text { Riung } \\
\text { kendaraan roda 2, roda } 4 \text { dengan } \\
\text { trayek angkutan umum Bajawa - } \\
\text { Beja - Jerebuu, Bajawa - } \\
\text { goronale - Soa - Marunggela - } \\
\text { Riung }\end{array}$ \\
\hline $\begin{array}{l}\text { Kampung Tua } \\
\text { Nage }\end{array}$ & 3,50 & baik & Ada & $\begin{array}{l}\text { kendaraan roda } 2 \text {, roda } 4 \text { angkutan } \\
\text { umum dengan trayek Bajawa - } \\
\text { Beja - Tiworiwu - Jerebuu, Riung } \\
\text { - Bajawa - Tiworiwu - Jerebuu }\end{array}$ \\
\hline $\begin{array}{l}\text { Kampung Tua } \\
\text { Gurusina }\end{array}$ & 3,50 & baik & Ada & $\begin{array}{l}\text { kendaraan roda } 2 \text {, roda } 4 \\
\text { angkutan umum dengan trayek } \\
\text { Bajawa - Dariwali - Jerebuu }\end{array}$ \\
\hline $\begin{array}{l}\text { Kampung Tua } \\
\text { Wogo }\end{array}$ & 3,50 & baik & Ada & $\begin{array}{l}\text { kendaraan roda } 2 \text {, roda } 4 \\
\text { angkutan umum dengan trayek }\end{array}$ \\
\hline $\begin{array}{l}\text { Ekowisata } \\
\text { Lekolodo }\end{array}$ & 3,50 & baik & Ada & $\begin{array}{l}\text { Bajawa - Turekisa - Mangulewa - } \\
\text { Mataloko - Were } \\
\text { kendaraan roda 2, roda } 4 \text { angkutan } \\
\text { umum dengan trayek Bajawa - } \\
\text { Bomari - Jerebuu }\end{array}$ \\
\hline
\end{tabular}

d. Promosi

Promosi dilakukan oleh Dinas

Backward Linkage

Kebudayaan dan Pariwisata melalui

Agen perjalanan wisata di Kabupaten Ngada media sosial instagram thenewtourismterritor yang bekerja sama dengan BKSDA dan masyarakat melalui mulut ke mulut terdapat di Kota Bajawa dengan jumlah 2 unit yaitu Nusa Flores Travel dan Flores Mandiri Travel yang berfungsi untuk memberikan infrormasi seputar pariwisata di Kabupaten Ngada. Adanya agen perjalanan wisata dapat membantu para wisatawan untuk mencari tiket hotel dan penginapan.Agen perjalanan wisata dapat dilihat pada gambar 3 .

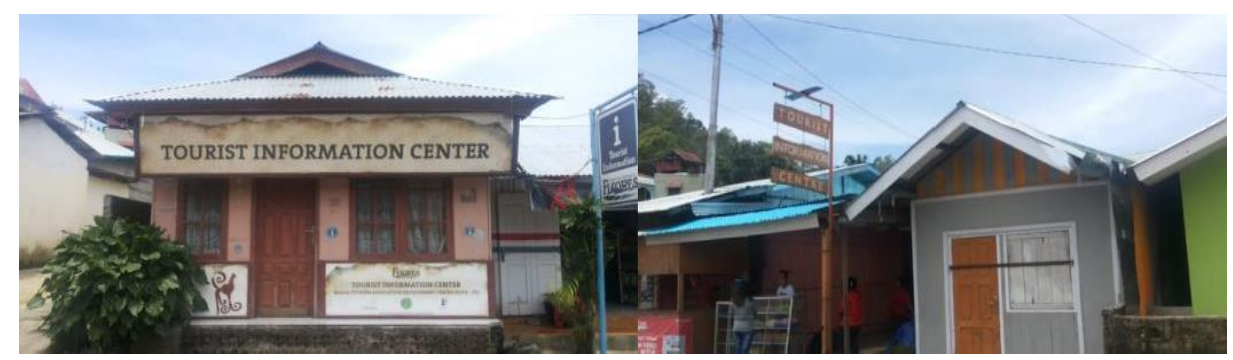

Nusa Flores Travel Flores Mandiri Travel

Gambar 3 AgenPerjalanan Wisata di Kota Bajawa

Kabupaten Ngada memiliki 2 atraksi wisata diantaranya tinju adat (saghi) yang terdapat di obyek wisata pemandian Air Panas Mangeruda dan upacara ulang tahun kampung adat (Reba) dan tarian penyambutan tamu(Jai) yang terdapat di obyek wisata Kampung Tua Bela, Kampung Tua Nage, Kampung Tua Bena, Kampung Tua Gurusina dan Kampung Tua Wogo. Tabel 2 atraksi wisata di Kabupaten Ngada. 
Tabel 2 Atraksi Wisata Kabupaten Ngada tahun 2018

\begin{tabular}{lll}
\hline No & Obyek wisata & Atraksi Wisata \\
\hline 1 & Taman Wisata Alam 17 Pulau Riung & - \\
2 & Pemandian Air Panas Mangeruda & Tinju adat (Saghi) \\
3 & Danau WawoMuda & - \\
4 & Kampung Tua Bela & Tarian jai \\
5 & Kampung Tua Bena & Tarian jai \\
6 & Kampung Tua Nage & Tarian jai \\
7 & Kampung Tua Gurusina & Tarian jai \\
8 & Kampung Tua Wogo & Tarian jai \\
9 & Ekowisata Lekolodo & Tarian jai \\
\hline
\end{tabular}

Sumber: Dinas Kebudayaan dan Pariwisata Kabupaten Ngada Tahun 2018

\section{Forward Linkage}

Jarak Tempuh dari kota Bajawa ke obyek wisata di Kabupaten Ngada adalah Taman Wisata Alam 17 Pulau Riung dapat di tempuh $75 \mathrm{Km}$, Pemandian Air Panas Mangeruda $25 \mathrm{Km}$, Kampung Tua Bela 7 Km, Kampung Tua Nage 27 Km, Kampung Tua Bena $21 \mathrm{Km}$, Kampung Tua Gurusina $25 \mathrm{Km}$, Kampung Tua Wogo $17 \mathrm{Km}$, Danau WawoMuda $7 \mathrm{Km}$, Ekowisata Lekolodo 6 $\mathrm{Km}$. Aksesbilitas di obyek wisata Kabupaten Ngada memiliki pekerasan aspal dengan lebar jalan 3,15 - 3,50 m dengan kondisi jalan baik dengan moda transportasi berupa kendaraan roda 2, sewa mobil, angkutan umum dengan trayek Bajawa - Riung,

Implementasi Sistem Informasi Geografis menggunakan fasilitas open source dari Google Maps, citra satelit sebagai data primer untuk menampilkan titik-titik potensi pariwisata di Kabupaten Ngada. Teknologi digital melalui smartphone android menjadi kebutuhan manusia dalam berbagai aktivitas dan
Bajawa - Soa, Bajawa - Jerebuu, Bajawa Mataloko, Soa - Riung, Jerebuu - Riung, Mataloko - soa Jerebuu - Soa. Sistem pengelolaan pariwisata di Kabupaten Ngada di kelola oleh Dinas kebudayaan dan pariwsata bekerja sama dengan Balai Konversi Sumber Daya Alam (BKSDA) mengelola Taman Wisata Alam 17 Pulau Riung, Dinas Kebudayaan dan Pariwisata dan masyarakat mengelolah Pemandian Air Panas Mangeruda, Danau WawoMuda, Kampung Tua Bela, Kampung Tua Bena, Kampung Tua Nage, Kampung Tua Gurusina, Kampung Tua wogo dan Ekowisata Lekoodo.

membantu mengembangkan Sistem Informasi Geografis menghasilkan peta tanpa kertas atau peta digital yang dapat digunakan sebagai referensi para pengguna (Jihan and Widyastuty 2018). Maka dari itu pengembangan peta digital dalam rangka optimalisasi teknologi dan mampu mengurangi penggunaan kertas. Berikut fungsi tampilan website: 
a. Halaman Utama Website

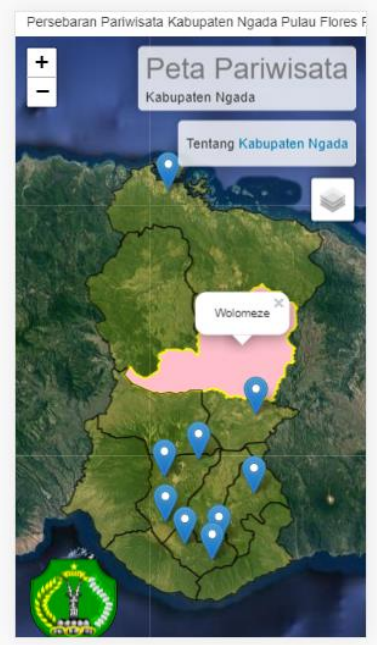

b. Legenda

Gambar 4. Antar Muka Website
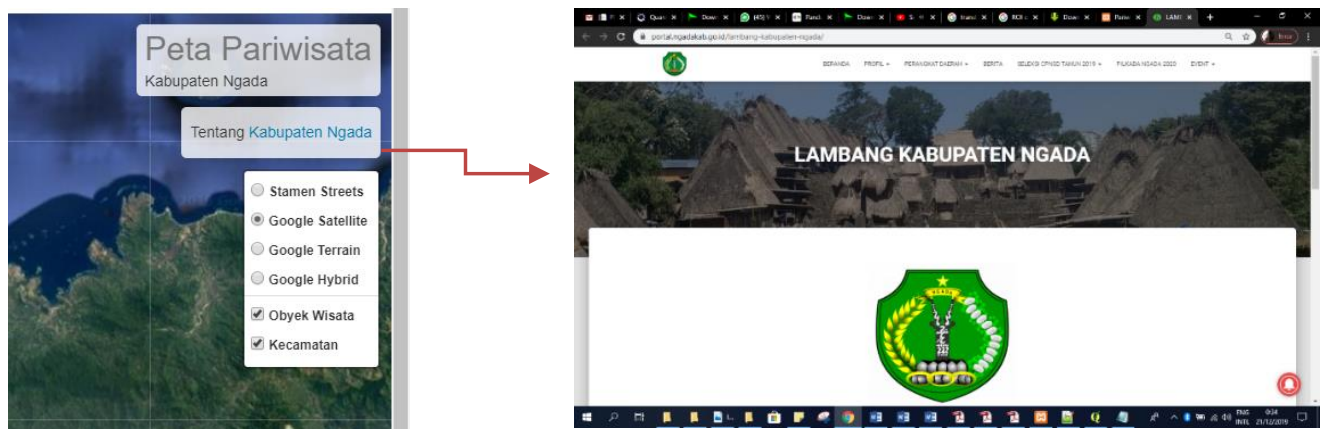

Gambar 5. Keterangan dan Terhubung Dengan Website Kabupaten

b. Halaman peta

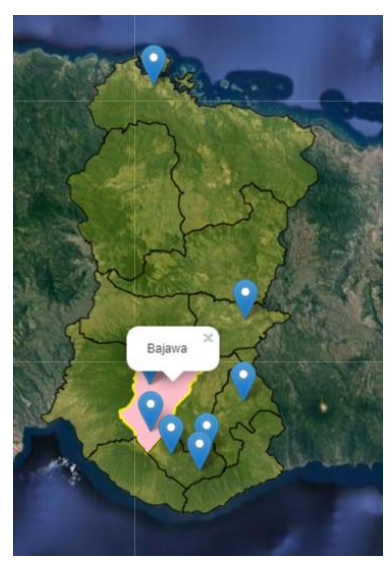

Gambar 6. Tampilan Peta

Data-data yang dikumpulkan adalah peta shp yang di-import melalui coding dan ditampilkan Google Maps. Peta yang di-import berdasarkan titik koordinat dengan parameter latitude (garis lintang) dan longitude (garis bujur). Berikut adalah rute antara satu lokasi wisata ke lokasi yang lainya, atau lokasi pengguna yang dijadikan sebagai data masukan spasial yang berasal dari server Google Maps. 
c. Info rute

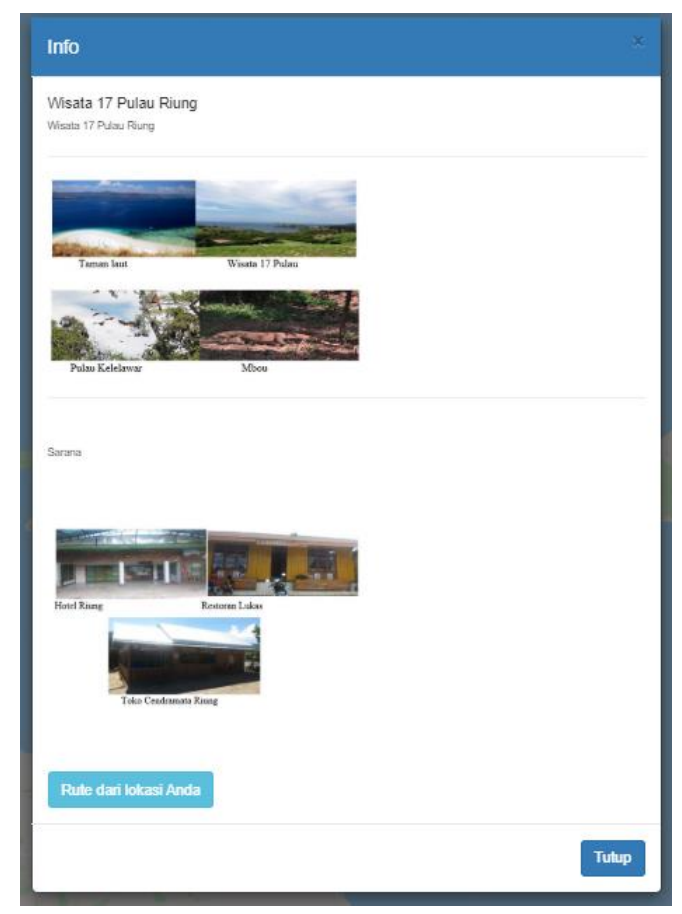

Gambar 7. Tampilan Info Foto Obyek Wisata, Sarana dan Rute

d. Info rute

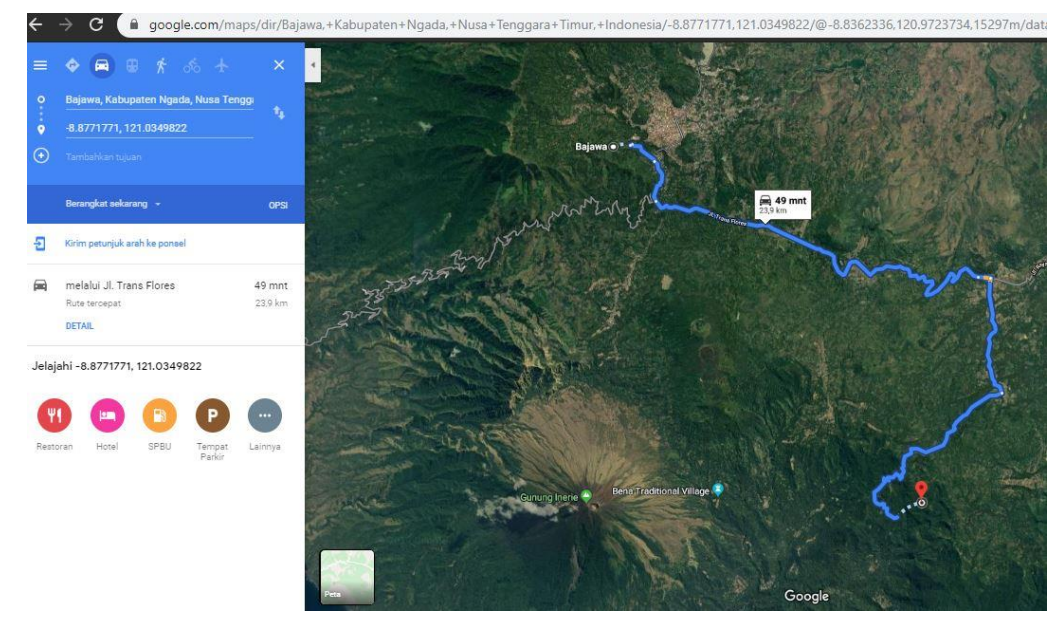

Gambar 8. Info Rute Terintegrasi Google Maps Berdasarkan Data SHP Yang di-import.

Tampilan objek wisata didapatkan dari digitasi shp dalam bentuk GeoJSON yang kemudian dijadikan layer peta dalam aplikasi WebGIS. Selebihnya dengan bantuan system operasi XAMPP control panel berfungsi sebagai server yang berdiri sendiri (localhost), yang terdiri atas program Apache HTTP Server, MySQL database. Implementa si antarmuka dilakukan dengan setiap halaman web yang dibuat. Implementasi antarmuka yang dibuat untuk semua pengguna, yaitu pengunjung, dan admin. 


\section{KESIMPULAN}

a. Potensi obyek wisata di Kabupaten Ngada adalah sebagai berikut:

Daya tarik obyek wisata di Kabupaten Ngada adalah sebagai berikut: Taman Wisata Alam 17 Pulau Riung menawarkan wisata Pulau kelelawar, wisata 17 pulau, terumbu karang dan hewan purba sejenis komodo. Pemandian Air Panas Mangeruda menawarkan kolam pemandian Air Panas, wisata religi, atraksi wisata tinju adat (Saghi). Danau WawoMuda menawarkan wisata kawah 3 warna dan sunrise. Perkampungan - perkampungan tua menawarkan wisata yang sama berupa batu peninggalan Megalitikum, terdapat rumah bagi laki-laki (Ngadhu) dan umah bagi perumpuan (Bhaga) dan atraksi wisata berupa tariantarian penyambutan tamu (Jai) serta Upacara ulang tahun kampung adat (Reba). Sarana pendukung obyek wisata di Kabupaten Ngada hanya tersedia di Taman Wisata Alam 17 Pulau Riung berupa 3 unit hotel, 2 unit restoran dan 1 unit toko cenderamata; Pemandian Air Panas Mangeruda berupa 1 unit hotel, 1 unit restoran dan 1 unit toko cenderamata. Obyek wisata lainya belum tersedia sarana pendukung. Aksesbilitas obyek wisata di Kabupaten Ngada memiliki kesamaan diantaranya menggunakan jalan pekerasan aspal, lebar jalan 3,50 m, memiliki lahan parkir seperti pada Taman Wisata Alam 17 Pulau Riung dan Pemandian Air Panas Mangeruda. Moda transportasi yang dapat digunakan yaitu kendaraan roda 2 , roda 4 dan trayek angkutan umum Bajawa - Riung, Bajawa - Soa, Bajawa - Jerebuu, Bajawa Mangulewa - Turekisa Mataloko. Promosi obyek wisata di Kabupaten Ngada dilakukan oleh
Dinas Kebudayaan dan Pariwisata melalui instagram thenewtourismterritor dan masyarakat melalui mulut ke mulut.

b. Linkage System Pariwisata di Kabupaten Ngada

Backward Linkage dilihat dari hotel, restoran, moda transportasi dan agen perjalanan. Agen perjalanan wisata di Kabupaten Ngada terdapat di Kota Bajawa yaitu Nusa Travel dan Flores Mandiri Travel yang berfungsi untuk memberikan informasi seputar pariwisata di Kabupaten Ngada. Forward Linkage dilihat dari jarak tempuh, aksesbilitas, system penegelolaan. Jarak tempuh dari kota Bajawa ke Taman Wisata Alam 17 Pulau Riung 75 Km, Pemandian Air Panas Mangeruda $25 \mathrm{Km}$, Kampung Tua Bela 7 Km, Kampung Tua Nage 27 $\mathrm{Km}$, Kampung Tua Bena $21 \mathrm{Km}$, Kampung Tua Gurusina $25 \mathrm{Km}$, Kampung Tua Wogo $17 \mathrm{Km}$, Danau WawoMuda $7 \mathrm{Km}$, dan Ekowisata Lekolodo $6 \mathrm{Km}$.Sistem pengelolaan pariwisata di obyek wisata Taman Wisata 17 Pulau Riung dilakukan oleh Dinas Kebudayaan dan Pariwsata bekerja sama dengan Balai Konversi Sumber Daya Alam (BKSDA), pengelola Pemandian Air Panas Mangeruda Dinas Kebudayaan dan Pariwsata. Sedangkan obyek wisata lainnya dikelola olehmasyarakat desa.

c. WebGIS memudahkan pemerintah dan pengguna untuk jalur transportasi, juga kebutuhan informasi yang diperlukan.

\section{UCAPAN TERIMAKASIH}

Ucapan terimakasih disampaikan oleh penulis kepada dinas pariwisata Kabupaten Ngada yang telah banyak membantu dalam proses pengumpulan data. 


\section{DAFTAR PUSTAKA}

Atas, Menengah, D. A. N. Madrasah, Aliyah Di, and Kabupaten Kudus. 2016. "Aplikasi Webgis Untuk Informasi Persebaran Sekolah Menengah Atas Dan Madrasah Aliyah Di Kabupaten Kudus Menggunakan Here Map Api." Jurnal Geodesi Undip 5(1):164-73.

Bahrudin, Agus. 2017. "Inovasi Daerah Sektor Pariwisata (Studi Kasus Inovasi Pembangunan Pariwisata Kab Purworejo Jawa Tengah).” Mimbar Administrasi 1(1):50-69.

Choridatul, Bahiyah, Hidayat R. Wahyu, and Sudarti. 2018. "Strategi Pengembangan Potensi Pariwisata Di Pantai Duta Kabupaten Probolinggo." Jurnal Ilmu Ekonomi 2:95-103.

Hermawan, Hary. 2017. "Pengembangan Destinasi Wisata Pada Tingkat Tapak Lahan Dengan Pendekatan Analisis Swot." Pariwisata IV(2):64-74.

Jihan, Jelita Citrawati and Sagung Alit Widyastuty. 2018. "Pemetaan Pengembangan Kawasan Rungkut Industri Surabaya (Sier) Berbasis Android." Jurnal Teknologi Informasi Dan Komunikasi 7:64-73.

Kirom, Novita Rifaul, Sudarmiatin Sudarmiatin, and I. Wayan Jaman Adi Putra. 2016. "FaktorFaktor Penentu Daya Tarik Wisata Budaya Dan Pengaruhnya Terhadap Kepuasan Wisatawan.” Jurnal Pendidikan - Teori, Penelitian, Dan Pengembangan 1(3):536-46.

Marlena, Deti and Hari Aspriyono. 2014. "Sistem Informasi Geografis Letak Lokasi Rumah Sakit Dan Apotek Kota Bengkulu Berbasis Android.” Jurnal Media Infotama 10(2):161-67.

Rifiyan, Andi M. and Yosua Manullang. 2015. "Pelaksanaan Promosi Kepariwisataan Samosir Oleh Dinas Pariwisata, Seni Dan Budaya Kabupaten Samosir." Jurnal Online Mahasiswa Fakultas Ilmu Sosial Dan Ilmu Politik Universitas Riau 2(2):3864-69.

Rosyidah, Eka, Aprilia Sunarti, and Edriana Pangestuti. 2017. "Pengaruh Daya Tarik Wisata Dan Fasilitas Layanan Terhadap Kepuasan Wisatawan Di Pantai Balekambang Kabupaten Malang.” Jurnal Administrasi Bisnis (JAB)|Vol 51(2):16-21. 